ISLAMIC BANKING: Jurnal Pemikiran dan Pengembangan Perbankan Syariah, Volume 7 Nomor 2 Edisi Februari 2022

\title{
PERSEPSI MAHASISWA PROGRAM STUDI EKONOMI PEMBANGUNAN UNIVERSITAS TRILOGI TERHADAP PROGRAM BELAJAR MERDEKA KAMPUS MERDEKA (MBKM)
}

\author{
Mangasi Panjaitan \\ Program Studi Ekonomi Pembangunan Universitas Trilogi \\ Email:mangasi2016@trilogi.ac.id \\ Ayu Dwidyah Rini \\ Program Studi Ekonomi Pembangunan Universitas Trilogi \\ Email: ayudwidyah@trilogi.ac.id \\ Lestari Agusalim \\ Program Studi Ekonomi Pembangunan Universitas Trilogi \\ Email:lestariagusalim@trilogi.ac.id \\ Zed Abdullah \\ Program Studi Ekonomi Pembangunan Universitas Trilogi \\ Email:zabd@trilogi.ac.id \\ Budhi Purwandaya \\ Program Studi Ekonomi Pembangunan Universitas Trilogi \\ Email:bpurwandaya@trilogi.ac.id \\ Benny Pasaribu \\ Program Studi Ekonomi Pembangunan Universitas Trilogi \\ Email:bennypasaribu@trilogi.ac.id
}

\begin{abstract}
The Merdeka Learning Campus Independent Program (MBKM) which was launched in 2020 gives its own color to Indonesian education, especially for college students. This program provides flexibility for students to choose the desired courses and campuses for their development. Students are given the right to study three semesters outside their on-campus and/or off-campus study programs. In its implementation the MBKM program encountered several obstacles. Constraints can come from students, campuses or the government. Implementing a "new" program on a national scale is not easy. The government prepares facilities and infrastructure, human resources and supporting regulations. The campus prepares and adapts its curriculum to the MBKM program while maintaining learning outcomes and profiles of study program graduates, students do not yet fully understand the MBKM program as a result of lack of socialization and weak student iteration to seek related information. Even some students do not know the existence of the program. Students have the perception that the MBKM program is important for them to improve their competence as a provision to face the future in the world of work. They hope for full support from the campus,
\end{abstract}


lecturers when they will join the MBKM program. However, they are worried that there will be additional costs that must be incurred when participating in the MBKM program.

Keywords: Independent Learning, Curriculum, Competence, Socialization

\begin{abstract}
Abstrak
Program Merdeka Belajar Kampus Merdeka (MBKM) Yang diluncurkan pada tahun 2020 memberikan warna tersendiri bagi pendidikan Indonesia, khususnya bagi mahasiswa perguruan tinggi. Program ini memberikan keleluasaan bagi mahasiswa untuk mememilih mata kuliah dan kampus yang diinginkan untuk pengembangan dirinya. Mahasiswa diberi hak untuk untuk kuliah tiga semester di luar program studinya didalam kampusdan/atau di luar kampusnya. Dalam pelaksanaannya program MBKM mengalami beberapa kendala. Kendala bisa berasal dari mahasiswa, kampus maupun pemerintah. Melaksanakan program "baru" yang berskala nasional tidaklah mudah. Pemerintah menyiapkan sarana dan prasana, SDM dan aturan pendukungnya. Kampus mempersiapkan dan menyesuaikan kurikulumnya dengan program MBKM dengan tetap mempertahankan capain pembelajaran dan profil lulusan program studi, mahasiswa belum sepenuhnya memahami program MBKM tersebut sebagai akibat kurangnya sosialisasi dan lemah iterasi mahasiswa untuk mencari informasi terkait. Bahkan sebagian mahasiswa tidak tahu adanya program tersebut. Mahasiswa punya persepsi bahwa program MBKM penting bagi mereka untuk meningkatkan kompetensi sebagai bekal menghadapi masa depan di dunia kerja. Mereka berharap adanya dukungan penuh dari kampus, dosen ketika akan mengikuti program MBKM. Namun mereka khawatir akan adanya biaya tambahan yang harus dikeluarkan ketika mengikuti program MBKM tersebut.
\end{abstract}

Kata Kunci: Merdeka Belajar, kurikulum, kompetensi, sosialisasi

\title{
Dasar Pemikiran
}

Perkembangan ilmu pengetahuan dan teknologi yang sangat pesat saat ini, telah membawa perubahan yang sangat pesat pula dalam berbagai aspek kehidupan. Pekerjaan dan cara bekerja berubah, banyak lapangan pekerjaan hilang, sementara berbagai jenis pekerjaan baru bermunculan. Perubahan ekonomi, sosial, dan budaya juga terjadi dengan laju yang tinggi. Dalam masa yang sangat dinamis ini, perguruan tinggi harus meresponse secara cepat dan tepat. Diperlukan transformasi pembelajaran untuk bisa membekali dan menyiapkan lulusan pendidikan tinggi agar menjadi generasi yang unggul. Generasi yang tanggap dan siap menghadapi tantangan zamannya, tanpa tercerabut dari akar budaya bangsanya .

Kebijakan Merdeka Belajar - Kampus Merdeka yang diluncurkan oleh Menteri Pendidikan dan Kebudayaan merupakan kerangka untuk menyiapkan mahasiswa menjadi sarjana yang tangguh, relevan dengan kebutuhan zaman, dan siap menjadi pemimpin dengan semangat kebangsaan yang tinggi. Permendikbud No 3 Tahun 2020 
ISLAMIC BANKING: Jurnal Pemikiran dan Pengembangan Perbankan Syariah, Volume 7 Nomor 2 Edisi Februari 2022

memberikan hak kepada mahasiswa untuk selama 3 semester belajar di luar program studinya. Melalui program ini, terbuka kesempatan luas bagi mahasiswa untuk memperkaya dan meningkatkan wawasan serta kompetensinya di dunia nyata sesuai dengan passion dan cita-citanya. Diyakini, pembelajaran dapat terjadi di manapun, semesta belajar tak berbatas, tidak hanya di ruang kelas, perpustakaan dan laboratorium, tetapi juga di desa, industri, tempat-tempat kerja, tempat-tempat pengabdian, pusat riset, maupun di masyarakat. Melalui interaksi yang erat antara perguruan tinggi dengan dunia kerja, dengan dunia nyata, maka perguruan tinggi akan hadir sebagai mata air bagi kemajuan dan pembangunan bangsa, turut mewarnai budaya dan peradaban bangsa secara langsung .

Program Merdeka Belajar Kampus Merdeka (MBKM), merupakan program yang digagas oleh Menteri Pendidikan dan Kebudayaan RI. Proses pembelajaran yang terjadi di perguruan tinggi di Indonesia ternyata belum sepenuhnya berhasil menghasilkan lulusan perguruan tinggi yang cepat tanggap terhadap perubahan yang terjadi di dunia kerja nyata. Terlebih lagi yang mampu menangani dan memanfaatkan dengan cakap kemajuan teknologi informasi dan komunikasi. Ketertinggalan ini akan dicoba diatasi dengan memperkenalkan program ini. Perguruan tinggi di Indonesia, tidak punya pilihan lain, kecuali melaksanakan program ini.

Untuk mengkaji implementasi program ini dan mengetahui bagaimana persepsi para mahasiswa yang menjalani program ini perlu dilakukan penelitian secara empirik. Penelitian yang terkait langsung dengan program Merdeka Belajar-Kampus Merdeka (MBKM) sudah dilakukan, diantaranya oleh Sumarto (2020), Assingly (2020), (Baharuddin, 2021), Fuad dan Aswita (2021) dan Siregar et.al (2021). Studi-studi tersebut tampaknya lebih menekankan kepada aspek institusional yang melaksanakan program MBKM. Perlu dilakukan kajian yang melibatkan para mahasiswa dan persepsi mereka tentang program MBKM tersebut untuk melengkapi studi-studi tersebut. Penelitian ini bertujuan untuk mengemukakan pemahaman langsung para mahasiswa di Universitas Trilogi, sebagai pelaku langsung di lapangan, terhadap program yang digagas oleh Menteri Pendidikan dan Kebudayaan Republik Indonesia tersebut. 


\section{Tinjauan Pustaka}

Secara substansi, program Merdeka Belajar Kampus Merdeka (MBKM) bukanlah hal baru dalam dunia pendidikan di Indonesia. Ada program Link and Match yang mirip dengan MBKM. Program tersebut mempersiapkan anak didik atau mahasiswa memasuki dunia kerja. Beda dengan MBKM yang diberikan kepada mahasiwa, maka link and match diberikan kepada siswa sekolah menengah. Program MBKM diluncurkan pada tahun 2020 dengan landasan hukum Permendikbud No.3 Tahun 2020.Sejak diberlakukannya program ini telah banyak hasil penelitian tentang pelaksanaan dan maupun filosofi MBKM itu sendiri.

Menurut Susilawati (2021) pendidikan merupakan proses pembelajaran dengan tujuan memanusiakan manusia. Oleh sebab itu peran dan interaksi antar manusia yang terlibat didalamnya turut menentukan keberhasilan program pendidikan itu sendiri. Dalam hubungan ini, Siregar et al. (2020) menemukan bahwa keberhasilan program MBKM ditentukan oleh empat faktor yaitu; kampus, industri, mahasiswa dan dosen. Assingly (2020), menemukan dalam mewujudkan MBKM pihak kampus harus; (1) menyelaraskan profil lulusan dengan kebutuhan masyarakat, (2) menentukan pendekatan, strategi dan metode pembelajaran sesuai dengan tuntutan masyarakat, (3) menentukan jenis dan teknik penilaian serta (4) melakukan pemetaan keselarasan kurikulum meliputi aspek capaian pembelajaran (CPL), materi, metode pembelajaran dan penilaian.

Selain itu turut dalam keberhasilan program adalah pengembangan kurikulum mencakup perencanaan, proses pembelajaran, penilaian dan evaluasi pembelajaran (Baharuddin, 2021). Sumarto (2020), menemukan bahwa program Kampus Merdeka haruslah sinkron, kolaboratif, dan integratif dengan Kurikulum KKNI, dimana setiap prodi harus memiliki Visi dan Misi, capaian dan profil lulusan. Program MBKM akan memberikan berbagai kompetensi kepada lulusan, yang menjadi bekal memasuki dunia kerja.

Widiyono et al. (2021), melihat implementasi penerapan MBKM melalui Program Kampus Mengajar Perintis di tingkat sekolah dasar. Hasil penelitiannya menunjukkan bahwa program MBKM membantu menyelesaikan problematika proses belajar mengajar akibat dari pandemi Covid-19. Ditemukan juga bahwa Program Kampus 
ISLAMIC BANKING: Jurnal Pemikiran dan Pengembangan Perbankan Syariah, Volume 7 Nomor 2 Edisi Februari 2022

Mengajar Perintis dapat membantu kelancaran aktivitas belajar selain itu juga dapat mengasah jiwa kepemimpinan dan karakter para mahasiswa.

Peran Perpustakaan sangat penting mendukung Kebijakan MBKM. Perpustakaan perguruan tinggi menjadi magnet terkuat dalam meningkatkan minat baca civitas akademik menuju merdeka belajar. Perpustakaan perguruan tinggi harus bisa memberikan dukungan optimal untuk menyediakan sumber daya informasi dalam penerapan MBKM. Pustakawannya juga harus proaktif berkolaborasi dengan mahasiswa dan dosen untuk mewujudkan atmosfir belajar sepanjang hayat. (Fatmawati, 2020).

Beberapa kendala yang dihadapi PTS penerapan program MBKM yaitu; 1) proses adaptasi kurikulum KKNI dengan program MBKM akan berdampak pada mahasiswa dan dosen. Mahasiswa masih ragu dalam memilih program MBKM sehingga masih banyak yang memilih menjalankan perkuliahan dengan menggunakan kurikulum KKNI. Hal yang sama juga terjadi pada dosen, dimana masih banyak dosen yang belum mau terlibat dalam program MBKM seperti menjadi dosen pembimbing lapangan (DPL) pada program kampus mengajar, dan masih banyak program MBKM yang lainnya yang membutuhkan peran aktif para dosen. 2) kampus mitra yang masih terbatas. Program pertukaran mahasiswa juga masih terkendala dengan masalah kampus mitra yang masih terbatas, persoalan pembiayaan juga masih belum dapat dirumuskan dengan baik. 3) program magang masih mengalami banyak kendala karena mekanisme kolaborasi perguruan tinggi swasta dengan pihak luar baik perusahaan, BUMN, BUMD bahkan pemerintah masih sangat terbatas, 4) pengelolaan dana oleh Yayasan yang belum menganggarkan dana tertentu untuk program MBKM (Fuad dan Aswita 2021).

Mukhlis (2020), menemukan beberapa dinamika pelaksanaan program MBKM yaitu antara lain:

a. Perguruan tinggi harus merevisi struktur kurikulum untuk disesuaikan yang diorientasikan pada kebijakan merdeka belajar mahasiswa dan penyusunan pedoman akademik termasuk di dalamnya Kalender Akademik yang perumusannya menggambarkan teori dan praktek termasuk timing pelaksanaannya; 
b. Perguruan tinggi melakukan kerjasama dengan berbagai pihak (perguruan tinggi dalam negeri maupun luar negeri, pemerintah, BUMN, lembaga penelitian, perusahaan, organisasi kemanusiaan, dan lain sebagainya:

c. Melakukan penyesuaian instrumen pembelajaran seperti Kontrak belajar, Rencana Program Semester (RPS), Silabus, Jurnal perkuliahan, Format evaluasi pembelajaran, dan lain sebagainya yang menggambarkan target pencapaian pembelajaran, dan evaluasi terhadap sistem dan format penilaian dan evaluasi seiring dengan pelaksanaan kebijakan merdeka belajar;

Kebijakan Kampus Merdeka memberikan peluang kepada para mahasiswa menjadi generasi bangsa kelas dunia melalui empat garis besar dalam kebijakan Kampus Merdeka. Kebijakan tersebut yaitu; Pertama, pemberian kewenangan penuh perguruan tinggi untuk mendirikan Program Studi (prodi) baru. Kedua, adanya proses reakreditasi secara otomatis. Ketiga, mempermudah proses peralihan status Perguruan Tinggi Negeri Badan Layanan Umum (PTNBLU) menjadi PTN Badan Hukum PTNBH). Keempat, adalah kebebasan mahasiswa untuk belajar di luar prodinya-bahkan di luar kampusnya (Nofia, 2020). Kebijakan Kampus Merdeka bisa mengikis gap antara dunia pendidikan dengan realitas dunia kerja. Kampus Merdeka relevan dengan kebutuhan komptensi di era 4.0 sekarang ini. Implementasi kebijakan ini mampu menunjang upaya program studi membekali mahasiswa dengan berbagai keahlian dan pengalaman di luar program studi guna menjawab tuntutan dan kebutuhan dunia pendidikan abad 21 (Priatmoko dan Dzakiyyah, 2020).

Rainsbury, et.al (2012), dalam penelitian di Autralia menemukan bahwa cooperative education programs sejenis MBKM membantu mahasiswa membangun kesadaran pentingnya memiliki kompetensi dalam memasuki dunia kerja (in the workplace). Dengan mengikuti program kampus merdeka, soft skills maupun hard skills meningkat, mempersiapkan mahasiswa menghadapi perkembangan zaman (Simatupang dan Yuhertiana, 2021). Sudariyanto, et.al (2020), memberikan dua saran terkait implementasi MBKM. Pertama, Kemendikbud, belum dapat dilakukan pertukaran pelajar antar-PTN/PTS di Indonesia secara mudah. Masih dibutuhkan 
ISLAMIC BANKING: Jurnal Pemikiran dan Pengembangan Perbankan Syariah, Volume 7 Nomor 2 Edisi Februari 2022

kerjasama khusus antar PTN/PTS guna bisa melakukan pertukaran pelajar. Kedua, PTN/PTS dapat menangani secara professional ke-delapan program MBKM

\section{Metode Penelitian}

Penelitian ini adalah penelitian eksploratori (exploratory research) dan penelitian lapangan (field research). Pendekatan yang digunakan adalah evaluasi, yaitu menjelaskan fenomena dengan teori-teori dan hasil riset melihat data empiris yang akan digunakan sebagai hasil evaluasi. Objek penelitian ini adalah mahasiswa dan dosen Program Studi Ekonomi Pembangunan Universitas Trilogi Jakarta. Data yang digunakan adalah data primer yaitu hasil pengisian kuesioner responden. Data primer ditabulasikan lalu diuraikan secara deskriptif. Hasil Penelitian dengan deskripsi data primer dianalisa guna mendapatkan satu gambaran mengenai objek penelitian.

\section{Hasil dan Pembahasan}

Berikut ini temuan tentang presepsi pemahaman mahasiwa dan dosen terhadap program MBKM di Prodi Ekonomi Pembangunan Universitas Trilogi. Bagian terbesar responden penelitian ini tentu saja adalah para mahasiswa. Dosen pembimbing mereka juga diikutkan dalam studi ini.

Mahasiswa di Program Studi Ekonomi Pembangunan yang memberikan response nya adalah mereka yang berada pada periode menjelang berakhirnya masa studi mereka. Mereka berusia antara $20-24$ tahun dan berdomisili di DKI Jakarta dan daerah sekitarnya. Umumnya mereka sangat familiar dalam pemakaian piranti (gadget) yang berkaitan dengan teknologi informasi dan komunikasi. 


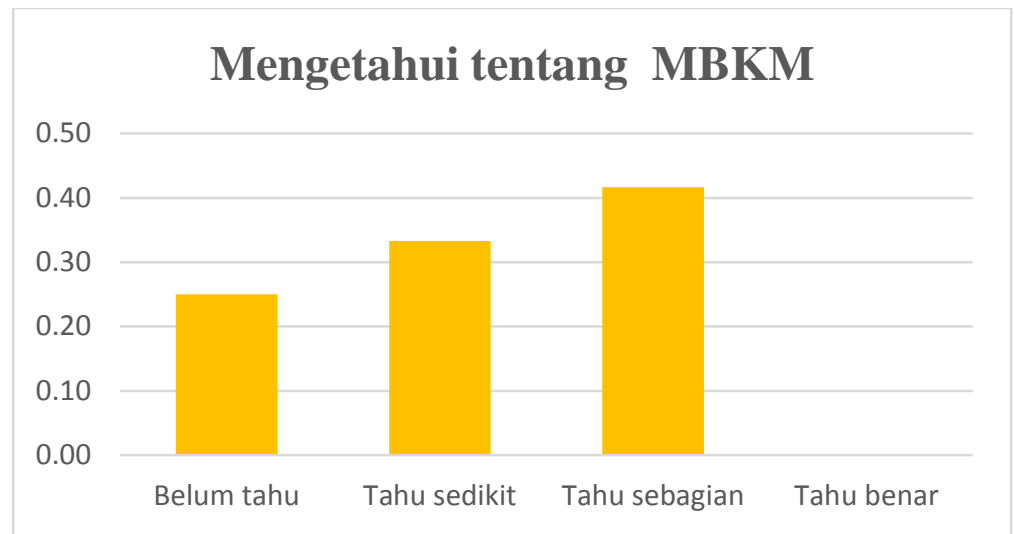

Gambar 1. Pengetahuan Tentang MBKM

Dari jawaban para mahasiswa atas pertanyaan dalam kuesioner penelitian ini, sebagian (33\%) Mahasiswa Program Studi Ekonomi Pembangunan menyatakan belum mengetahui kebijakan Merdeka Belajar Kampus Merdeka (MBKM), sedangkan 67\% dari mereka sudah mengetahuinya. Sebanyak 22\% mahasiswa Program Studi Ekonomi Pembangunan menginginkan kebijakan MBKM dapat disetarakan satu semester diluar kampusnya, $44 \%$ menginginkan dua semester, $22 \%$ dari mahasiswa menginginkan tiga semester dan $11 \%$ menginginkan empat semester di luar kampus.

Sebanyak 22\% mahasiswa Program Studi Ekonomi Pembangunan menginginkan dapat disetarakan hingga 40 SKS kebijakan MBKM di luar kampus, 11\% menginginkan 4 sks dapat disetarkan, sedangkan sisanya, 67\% dari mahasiswa, menginginkan kurang dari 4 sks. Pengetahuan atau informasi mahasiswa Program Studi Ekonomi Pembangunan Universitas Trilogi tentang kebijakan MBKM berasal dari berbagai sumber yaitu; Kemendikbud (44\%), Website Perguruan Tinggi (22\%), Sosialisasi oleh perguruan tinggi (11\%), dan juga sebagian dari media sosial (22\%).

Sumber sumber informasi yang digunakan mahasiswa untuk meningkatkan pengetahuannya tentang kebijakan MBKM antara lain adalah; kanal Kemendikbud (78\%), kanal perguruan tinggi (11\%) dan kanal komunitas (alumni, dosen) sebesar $11 \%$. Menurut pemahaman sebagian mahasiswa (44\%) Program Studi Ekonomi Pembangunan, program serupa MBKM telah diberlakukan sebelumnya pada program studi Ekonomi Pembangunan Universitas Trilogi, sedangkan sebagian lainnya (56\%), tidak atau belum mengetahui adanya program serupa. Ada delapan program atau bentuk kegiatan pembelajaran di luar kampus, mahasiswa EKP lebih banyak (44\%) memilih 
ISLAMIC BANKING: Jurnal Pemikiran dan Pengembangan Perbankan Syariah, Volume 7 Nomor 2 Edisi Februari 2022

magang, diikuti oleh studi independen (22\%), lalu kegiatan wirausaha, KKN (Kuliah Kerja Nyata) dan Proyek Kemanusiaan masing-masing $11 \%$.

Menurut sebagian mahasiswa (33\%), pedoman, dokumen serta prosedur operasional untuk mengikuti program MBKM telah tersedia di program studi, sedangkan menurut sebagian lagi $(67 \%)$ belum tersedia. Bagi mahasiswa yang sudah mengetahui adanya program MBKM ternyata belum sepenuhnya mempersiapkan diri untuk mengikutinya. Hanya $44 \%$ yang mempersiapkan diri untuk mengikutinya serdangan $56 \%$ belum mempersiapkan diri.

Mengenai implikasi program MBKM terhadap masa studi, sebagian dari mahasiswa (33\%) mengatakan bisa selesai tepat waktu, sedangkan $67 \%$ dari mereka mengatakan tidak tahu. Sebagian besar mahasiswa (56\%) mengatakan bahwa pembelajaran di luar kampus akan meningkatkan keterampilan dan kompetensi dalam menyelesaikan masalah, sedangkan sisanya (44\%) mengatakan mungkin. Mayoritas (78\%) mahasiswa Program Studi Ekonomi Pembangunan yakin bahwa belajar di program studi lain akan meningkatkan perspektif dan menambah kompetensi bagi mereka, sedangkan sisanya (22\%) mengatakan mungkin.

Agar program MBKM berjalan optimal, 89\% mahasiswa mengatakan harus terlebih dahulu mempelajari panduan MBKM dan kurikulum yang memfasilitasi MBKM. Sedangkan $11 \%$ mengatakan mengikuti seleksi kegiatan dan menyiapkan syarat-syarat yang dibutuhkan. Semua mahasiswa mengaku bahwa mengikuti program MBKM bermanfaat. Sebanyak 67\% mahasiswa mengatakan akan menjadi bekal yang sangat bermafaat kelak setelah lulus, sedangkan 33\% mengatakan bermanfaat.

Setelah mengikuti program MBKM, sebanyak 78\% mengatakan akan mengalami peningkatkan soft skill yang baik, sedangkan 22\% mengatakan akan mengalami peningkatan soft skill cukup baik. Mayoritas mahasiswa (56\%) menganggap sangat penting mengikuti program MBKM sebagai persiapan menghadapi masa paska kampus, sedangkan lainnya mengatakan penting dan cukup penting masing-masing $22 \%$.

Kekhawatiran terbesar mahasiswa ketika akan mengikuti program MBKM adalah akan mengeluarkan biaya, kurangnya informasi serta kurangnya dukungan kampus. Sebesar $67 \%$ dari mereka khawatir akan adanya tambahan biaya, 11\% khawatir akan 
360 Mangasi Panjaitan, et.al, PERSEPSI MAHASISWA PROGRAM STUDI EKONOMI PEMBANGUNAN...........

kurangnya informasi serta $22 \%$ khawatir kurangnya dukungan dari kampus. Para mahasiswa merasa tidak ada hambatan dari orangtua atas proses pembelajaran MBKM ini.

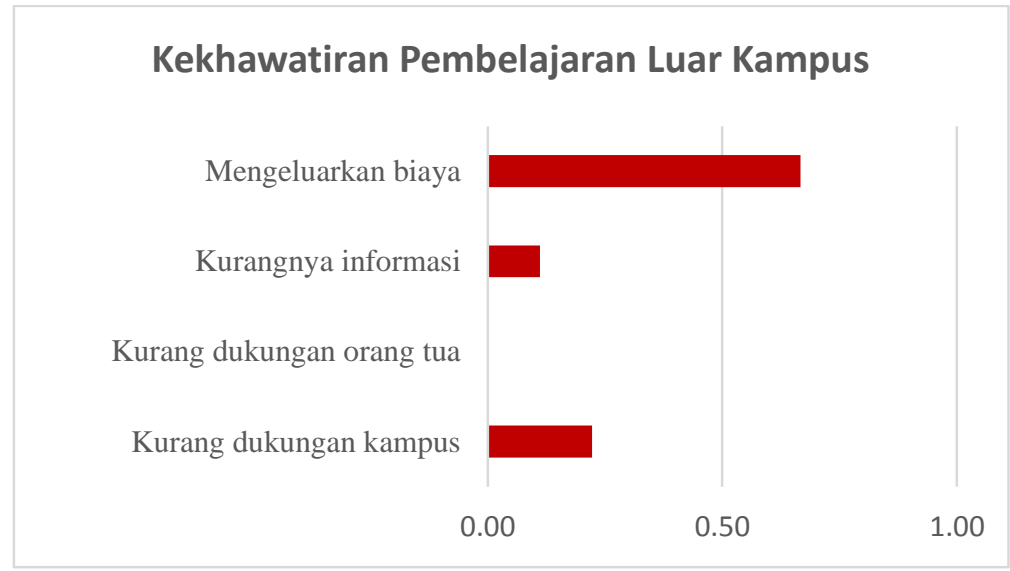

Gambar 2. Kekhawatiran Pembelajaran Luar Kampus

Menurut 78\% mahasiswa, mengikuti program MBKM sesuai dengan kebutuhan lulusan di masa depan, sedangkan 22\% mengatakan sangat sesuai. Setelah mahasiswa mengetahui adanya program MBKM, sebagian dari mereka (56\%) tidak terlalu tertarik atau biasa saja untuk mempromosikannya kepada koleganya, sedangkan $44 \%$ dari mereka tidak tertarik mempromosikannya.

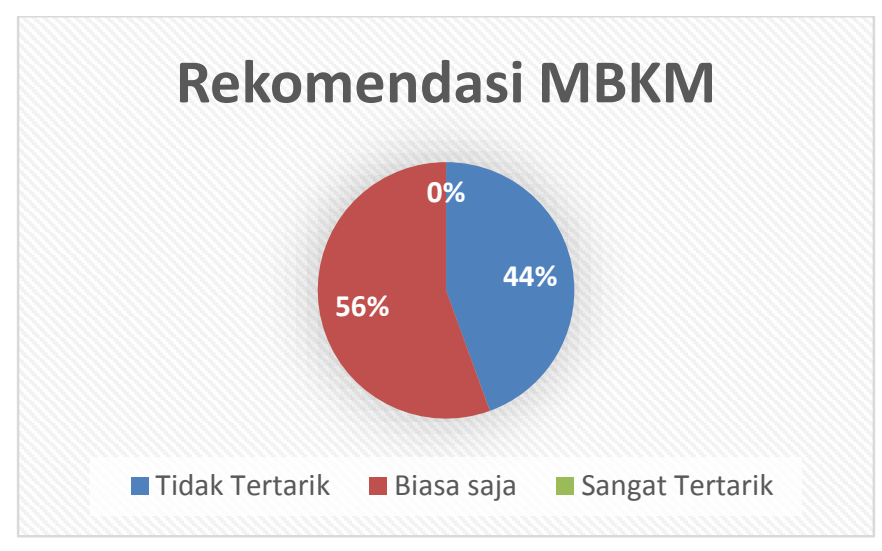

\section{Gambar 3. Promosi MBKM kepada kolega}

Ini merupakan temuan yang menarik. Kurang antusiasnya mereka untuk menyebarluaskan program ini bias jadi dikarenakan pengalaman yang mereka rasakan langsung dalam mengikuti program ini. Banyak hal yang perlu dikaji lebih lanjut mengapa kesan tersebut timbul dikalangan peserta program ini di Prodi Ekonomi Pembangunan Universitas Trilogi. Bila hal ini dikaitkan dengan apa yang mereka 
ISLAMIC BANKING: Jurnal Pemikiran dan Pengembangan Perbankan Syariah, Volume 7 Nomor 2 Edisi Februari 2022

ketahui tentang program MBKM, pada pertanyaan pertama, mungkin saja karena harapan mereka tentang MBKM dengan kenyataan yang dirasakan di lapangan berbeda. Kekurangtahuan dengan benar tentang MBKM dapat saja memberikan harapan mahasiswa yang tidak sepenuhnya sejalan dengan tujuan dilakukannya program ini.

\section{Simpulan}

Mahasiswa Program studi Ekonomi Pembangunan belum mengenal secara baik program MBKM, bahkan sebagian diantara mereka belum pernah mendengarnya. Diperlukan komunikasi yang lebih intens dari Kemendikbud, Kampus kepada mahasiswa. Mahasiswa yang sudah tahu MBKM paham bahwa program tersebut penting sebagai bekal mereka menghadapi dunia kerja. Program magang/kerja industri adalah program MBKM yang paling diminati. Mahasiswa mendapatkan informasi tentang program MBKM lebih dari luar kampusnya daripada kampus sendiri. Kampus, khususnya program studi, harus meningkatkan usahanya untuk memperkenalkan program MBKM kepada mahasiswa. Mahasiswa berharap agar bobot MBKM di luar kampus tidak kurang dari 40SKS. Mahasiswa mengkhawatirkan bertambahnya biaya yang akan mereka keluarkan jika mengikuti program MBKM, juga kurangnya dukungan informasi dan dukungan kampus kepada mereka dalam mengikuti program MBKM.

\section{DAFTAR PUSTAKA}

Assingkily, M. S. (2020). Upaya Mewujudkan Program Kampus Merdeka Pada Kurikulum PGMI STIT Al Ittihadiyah Labuhanbatu Utara. At-Thullab: Jurnal Pendidikan Guru Madrasah Ibtidaiyah, Vol. 4, No. 2.

Baharuddin, M. R. (2021). Adaptasi Kurikulum Merdeka Belajar Kampus Merdeka (Fokus: Model MBKM Program Studi). Jurnal Studi Guru dan Pembelajaran, Vol. 4, No. 1.

Direktorat Jenderal Pendidikan Tinggi.2020. Buku Panduan Merdeka Belajar Kampus Merdeka. Kementerian Pendidikan dan Kebudayaan, Jakarta. 
Fatmawati, E. (2020). Dukungan Perpustakaan Dalam Implementasi "Kampus Merdeka Dan Merdeka Belajar”. Jurnal Pustaka Ilmiah, Vol. 6, No. 2.

Fuadi, T. M. \& Aswita, D. (2021). Merdeka Belajar Kampus Merdeka (MBKM): Bagaimana Penerapan Dan Kedala Yang Dihadapi Oleh Perguruan Tinggi Swasta Di Aceh. Jurnal Dedikasi Pendidikan, Vol. 5, No. 2.

Kementerian Pendidikan dan Kebudayaan.2020. Permendikbud No.3 Tahun 2020. Kementerian Pendidikan dan Kebudayaan, Jakarta.

Muslikh. (2020). Landasan Filosofis Dan Analisis Terhadap Kebijakan Merdeka Belajar Dan Kampus Merdeka. Jurnal Syntax Transformation, Vol. 1, No. 3.

Nofia, N. N. (2020). Analisis Tantangan Implementasi Kebijakan "Merdeka Belajar Kampus Merdeka" pada Perguruan Tinggi Islam Negeri di Indonesia. PRODU: Prokurasi Edukasi-Jurnal Manajemen Pendidikan Islam, Vol. 1, No. 2.

Priatmoko, S. \& Dzakiyyah, N. I. (2020). Relevansi Kampus Merdeka Terhadap Kompetensi Guru Era 4.0 Dalam Perspektif Experiential Learning Theory, Vol. 4, No. 1.

Rainsbury E., Hodges D. \& Burchell N. (2002). Ranking Workplace Competencies: Student and Graduate Perceptions. Asia-Pacific Journal of Cooperative Education, Vol. 3, No. 2.

Simatupang, E. \& Yuhertiana, I. (2021). Merdeka Belajar Kampus Merdeka terhadap Perubahan Paradigma Pembelajaran pada Pendidikan Tinggi: Sebuah Tinjauan Literatur. Jurnal Bisnis, Manajemen dan Ekonomi, Vol. 2, No. 2.

Siregar, N., Sahirah, R. \& Harahap, A. A. (2020). Konsep Kampus Merdeka Belajar Di Era Revolusi Industri 4.0. Fitrah: Journal of Islamic Education (FJIE), Vol. 1, No. 1.

Sopiansyah, D., Masruroh, S., Zaqiah, Q. Y. \& Erihadiana, M. (2022). Reslaj: Religion Education Social Laa Roiba Journal, Vol. 4, No. 1.

Sudaryanto, Widayati, W. \& Amalia, R. (2020). Konsep Merdeka Belajar-Kampus Merdeka dan Aplikasinya dalam Pendidikan Bahasa (dan Sastra) Indonesia. KODE: Jurnal Bahasa, Vol. 9, No. 2.

Sumarto. (2020). Kampus Merdeka ; Realitas Pembelajaran Online, Riset dan Pengembangan Wirausaha. Jurnal Literasiologi, Vol. 4, No. 2.

Susilawati, N. (2021). Merdeka Belajar dan Kampus Merdeka Dalam Pandangan Filsafat Pendidikan Humanisme. Jurnal Sikola: Jurnal Kajian Pendidikan dan Pembelajaran, Vol. 2, No. 3.

Widiyono, A., Irfana, S. \& Firdausia, K. (2021). Implementasi Merdeka Belajar Melalui Kampus Mengajar Perintis Di Sekolah Dasar. Jurnal Pendidikan Ke-SD-an, Vol. 16, No. 2. 